\title{
Particular Aspects of Inflammatory Biochemical Markers in Preeclamsia
}

\author{
ELENA MIHALCEANU ${ }^{1}$, GABRIEL COSTĂCHESCU ${ }^{1}$, ALEXANDRA PANGAL ${ }^{1 *}$, IOAN TUDOR LAZĂR ${ }^{1 *}$, \\ IRINA NEGRU ${ }^{2}$, VIRGIL BULIMAR ${ }^{3}$, ROXANA MATASARIU ${ }^{1 *}$, DEMETRA SOCOLOV ${ }^{1}$ \\ 1"Grigore T. Popa" University of Medicine and Pharmacy,Faculty of Medicine, Department mother and child, 16 \\ Universitatii Str., 700115, Iasi, Romania \\ 2"Grigore T. Popa" University of Medicine and Pharmacy,Faculty of Medicine, II-nd Surgical Department,16 Universitatii \\ Str., 700115, Iasi, Romania \\ 3"Grigore T. Popa" University of Medicine and Pharmacy, Faculty of Medicine, I-st Surgical Department, 16 Universitatii \\ Str., 700115, Iasi, Romania
}

Preeclampsia is a rapidly progressive disorder characterized by high blood pressure and usually the presence of proteinuria. It occurs after 20 weeks of gestation and up to six weeks postpartum. It requires proper prenatal care which is essential to diagnose and manage this disease. Our study show the correlations between the statistical data and the epidemiology issues, in order to outline a pregnancy profile with preeclampsia. We considered clinical and biophysical markers of preeclampsia in a 138 patient group. Our results encourage us to deepen this topic by enlarging the patient group number and to perform cohort multicentric evaluations.

\section{Keywords: preeclampsia biophysical markers, clinical markers, statistic evaluation}

Preeclampsia is characterized by a generalized vascular endothelial dysfunction (1), a dysfunction that occurs long before the onset of clinical signs. Pathophysiological changes in preeclampsia are the result of baneful changes of the placenta, which induces a generalized alteration of the endothelium, which results in vasoconstriction, hypovolemia and thrombus formation.

The systemic impairment of the endothelium signify itself differently in various organs and tissues: fetoplacental barrier, brain, liver, kidney or haematological. Endothelial dysfunction in preeclampsia is also associated with an exaggerated maternal systemic inflammatory response and therefore endothelial dysfunction and inflammation are considered to play a crucial role in its pathophysiological mechanism.

Diffuse endothelial injury affects all susceptible blood vessels, the result of multiple organ dysfunction, but with a varying degrees of severity. In addition, there may be differences between maternal and fetal injury in terms of severity of clinical manifestations.

At present, there is no single objective test for the detection of preeclampsia or for quantifying the risk of certain severe complications. The diagnosis is still based only on clinical and possibly laboratory parameters evaluated in their dynamics. Experience shows that early detection and monitoring of the mother and fetus are beneficial and therefore the prediction of preeclampsia becomes very important.

Thus, Simon Grill and Corinne Rusterholz presented in 2009 a study of the different potential biochemical markers for prediction in Q1 and Q2 and detection markers in the case of manifest preeclampsia, as well as their association with ultrasound examination. They state that although there are different potential markers for preeclampsia, their validity as predictors appears different and uncertain at different stages of gestation. It concludes, in the end, that preeclampsia, which is a multifaceted disorder, is in fact not a disease but is an association of "various diseases" and, in order to propose the routine medical practice of these markers, extensive further studies are needed (2).

Starting from the hypothesis that preeclampsia is caused by endothelial dysfunction, the literature presents other studies in this regard, such as those studying of fibronectin, which is a known marker of endothelial dysfunction. In 1999, Sudd presents a study that shows that fibronectin increases in preeclampsia compared to normal pregnancy.

The aim of the study is to establish an efficient strategy from the perspective of the clinician, by creating a diagnostic algorithm that facilitates the therapeutic decision according to the values of the hematological, biochemical, ultrasound, morphological, anatomopathological and angiogenic parameters. The study focuses on highlighting the correlations between the statistical data and the epidemiology issues, in order to outline a pregnancy profile with preeclampsia, highlighting the risk factors commonly encountered for this condition.

Leveraging the results will lead to the proposal of an efficient method of screening, in order to reduce the incidence of preeclampsia complications. The main objective is to propose an efficient algorithm for diagnosis and treatment.

*email: a_pangal@yahoo.com; tudorlazar@gmail.com; roxanamatasariu@yahoo.com 


\section{Experimental part}

Material and methods

We performed the study of the clinical and evolutionary aspects of preeclampsia, by verifying the correlation between inflammatory parameters and blood pressure, on a group of pregnant women with preeclampsia, compared with a lot of normal pregnant women, admitted to the Clinical Hospital of Obstetrics and Gynecology "Cuza Voda" Iasi.

The case was formed between 2012 and 2018. The patients were selected by studying the observation sheets of the pregnant women hospitalized in the Clinical Hospital of Obstetrics and Gynecology "CuzaVoda", with gestational age over 20 weeks, which were addressed for specialized consultation and at which CRP was harvested, without being an infectious context or spontaneous premature rupture. The inclusion criteria were aimed at gestational age more than 20 weeks, high blood pressure and proteinuria.

Exclusion criteria consisted of gestational age younger than 20 weeks, hypertension pre-existing pregnancy and seropositivity to $\mathrm{HN}$.

Depending on the clinical status, HTA in association with proteinuria and / or edema, there were 3 study groups:

1. PE group - 54 pregnant women with preeclampsia (PE), aged 19-41 years.

2. HTAIS group - 34 pregnant women with a personal pathological history of HTA, with age between 22 and 44 years.

3. The GN group was formed by 50 normal pregnant women aged $16-41$ years.

The data were systematized and centralized in a SPSS 13.0 database and were processed by statistical functions at which they are prepared. In the data presentation, the confidence intervals at the significance threshold $95 \%$ were used.

For the descriptive statistical analysis the ANOVA test was used.

\section{Results and discussions}

In the group of normal pregnancies the age ranged from 19 to 41 years, with a mean value of $26.50 \pm 5.61$ years, and in the group of pregnant women with preeclampsia the age ranged between 19 and 41 years, with an average of the group of $28.88 \pm 5.93$ years. This is showing statistically significant differences compared with the average age registered in the HTAIS patient group, where the average value reached the threshold of $31.35 \pm 5.88$ years $(\mathrm{p}=$ 0.001) (Figure 1).

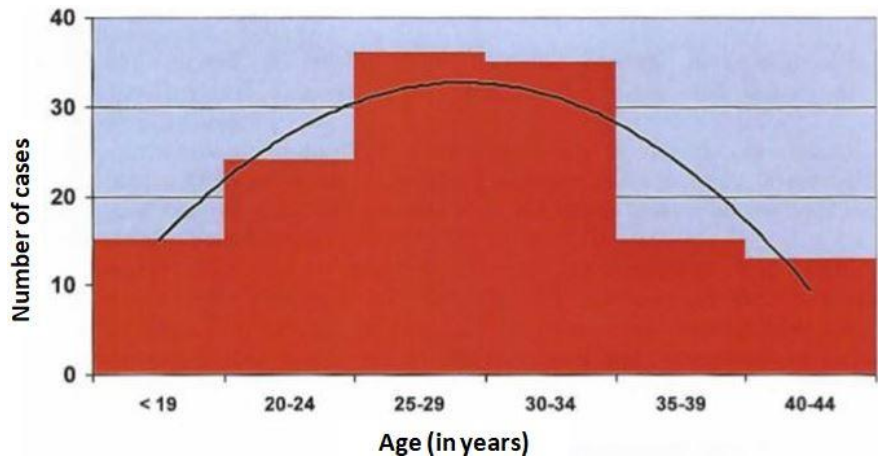

Fig. 1 Age distribution of the patients

Edema was present in $50 \%$ of preeclampsia pregnant women and $29.4 \%$ of those with HTA, significantly higher percentage differences compared with the control group $(\mathrm{p}=0.001)$ (Figure 2).

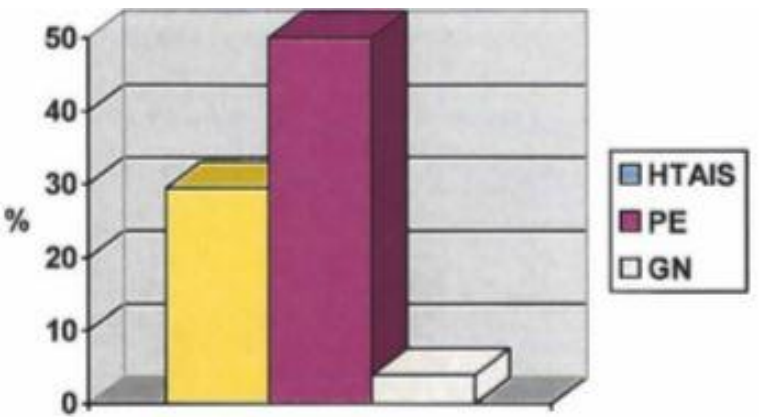

Fig. 2 Frequency of edema compared within the study groups 
Proteinuria was found in $87.5 \%$ of patients in the preeclampsia group and $64.7 \%$ of those with HTAIS (Table 1).

Table 1

STATISTICAL ANALYSES OF PROTEINURIA

\begin{tabular}{|l|r|r|r|r|r|r|}
\hline \multirow{2}{*}{ Proteinuria } & \multicolumn{2}{|c|}{ GN } & \multicolumn{2}{|c|}{ HTAIS } & \multicolumn{2}{|c|}{ PE } \\
\hline No & \multicolumn{1}{|c|}{$\mathrm{n}$} & \multicolumn{1}{c|}{$\%$} & $\mathrm{n}$ & \multicolumn{1}{c|}{$\%$} & $\mathrm{n}$ & $\%$ \\
\hline Traces & 17 & $70.8 \%$ & 12 & $35.3 \%$ & & \\
\hline 30 & 7 & $29.2 \%$ & 5 & $14.7 \%$ & 2 & $12.5 \%$ \\
\hline 100 & & & 5 & $14.7 \%$ & 1 & $6.3 \%$ \\
\hline 300 & & & 2 & $5.9 \%$ & 4 & $25.0 \%$ \\
\hline
\end{tabular}

Height $(\mathrm{p}<0.008)$ and weight $(\mathrm{p}=0.001)$ were significantly higher in HTA patients.

In the study group the weight status highlights the following aspects $(p=0.001)$ :

-the characteristic of the patients with preeclampsia was the overweight $(\mathrm{BMI}=30.52 \mathrm{~kg} / \mathrm{m} 2)$, with variations from $23.03-42.59 \mathrm{~kg} / \mathrm{m} 2$;

-the characteristic of patients with HTA was obesity gr. I, the average value being $32.57 \mathrm{~kg} / \mathrm{m} 2$, but it should be noted that in $11.8 \%$ of them was observed soft obesity;

-in the control group the normal weight was characteristic, the group average being $26.91 \mathrm{~kg} / \mathrm{m} 2$, with variations from 21.01 to $40.87 \mathrm{~kg} / \mathrm{m} 2$.

Depending on the variation in BMI during pregnancy, it should be noted that in pregnant women with preeclampsia there were weight increases of over $32 \%$, while in pregnant women with HTA the BMI increase was about $18 \%$ (Table 2).

Table 2

\begin{tabular}{|c|c|c|c|c|c|c|c|c|c|}
\hline \multirow{2}{*}{$\begin{array}{l}\text { Study } \\
\text { group }\end{array}$} & $\mathbf{N}$ & \multirow[t]{2}{*}{ Average } & \multirow[t]{2}{*}{$\begin{array}{l}\text { Standard } \\
\text { deviation }\end{array}$} & \multirow[t]{2}{*}{$\begin{array}{l}\text { Standard } \\
\text { error }\end{array}$} & \multicolumn{2}{|c|}{$\begin{array}{l}\text { Confidence } \\
\text { interval }\end{array}$} & \multirow[t]{2}{*}{ Min } & \multirow[t]{2}{*}{$\operatorname{Max}$} & \multirow[t]{2}{*}{$\mathrm{p}$} \\
\hline & & & & & & & & & \\
\hline GN & 50 & 163.73 & 6.24 & 0.89 & 161.94 & 165.53 & 150 & 180 & \multirow{4}{*}{0.008} \\
\hline HTAIS & 34 & 168.29 & 6.65 & 1.14 & 165.97 & 170.61 & 150 & 178 & \\
\hline $\mathrm{PE}$ & 54 & 165.31 & 6.56 & 1.64 & 161.82 & 168.81 & 150 & 175 & \\
\hline TOTAL & 138 & 165.56 & 6.70 & 0.67 & 164.22 & 166.89 & 150 & 180 & \\
\hline \multicolumn{10}{|c|}{ Weight (kg) } \\
\hline GN & 50 & 72.19 & 12.43 & 1.79 & 68.58 & 75.80 & 50 & 102 & \multirow{4}{*}{0.001} \\
\hline HTAIS & 34 & 92.07 & 21.71 & 3.72 & 84.50 & 99.65 & 60 & 160 & \\
\hline PE & 54 & 83.50 & 17.77 & 4.44 & 74.03 & 92.97 & 69 & 126 & \\
\hline TOTAL & 138 & 80.93 & 19.14 & 1.93 & 77.09 & 84.77 & 50 & 160 & \\
\hline \multicolumn{10}{|c|}{ Body mass index $(\mathrm{kg} / \mathrm{m} 2)$} \\
\hline GN & 50 & 26.91 & 4.04 & 0.58 & 25.73 & 28.08 & 21.01 & 40.87 & \multirow{4}{*}{0.001} \\
\hline HTAIS & 34 & 32.57 & 7.83 & 1.34 & 29.83 & 35.30 & 22.60 & 60.97 & \\
\hline PE & 54 & 30.52 & 6.03 & 1.51 & 27.31 & 33.73 & 23.03 & 42.59 & \\
\hline TOTAL & 138 & 29.46 & 6.42 & 0.65 & 28.17 & 30.75 & 21.01 & 60.97 & \\
\hline
\end{tabular}

Gestation and parity did not reveal significant differences between the analyzed groups ( $>$ > 0.05). In patients with pre-cancer, the number of pregnancies / births varied between 1 and 4, the average value being slightly higher than 1 , whereas in patients in the HT AIS group the average approaches 2 births / pregnancies.

The structure of the analyzed groups, according to the gestational age, presented the following distributions: most commonly, the patients with preeclampsia were in the gestational week 33-36 (37.5\%); the distribution of patients with HTA depending on the gestational week was somewhat homogeneous, 29.4\% in weeks 33-36 and 37-40, but also 
a share of $20.6 \%$ in weeks $29-32$; in $80 \%$ of the pregnant women in the control group, at the time of the study, the gestational age was over 37 weeks.

Systolic blood pressure (SBP) was significantly higher in the patients in the preeclampsia group ( $\mathrm{p}<0.001)$, with variations from 120 to $180 \mathrm{mmHg}$, the group mean being $153.44 \pm 18.95 \mathrm{mmHg}$. Most pregnant women in the preeclampsia group had systolic blood pressure values between 143-164 $\mathrm{mmHg}$ (37\%), but a proportion of $24 \%$ of women with preeclampsia had values above $160 \mathrm{mmHg}$ (Figure 3).

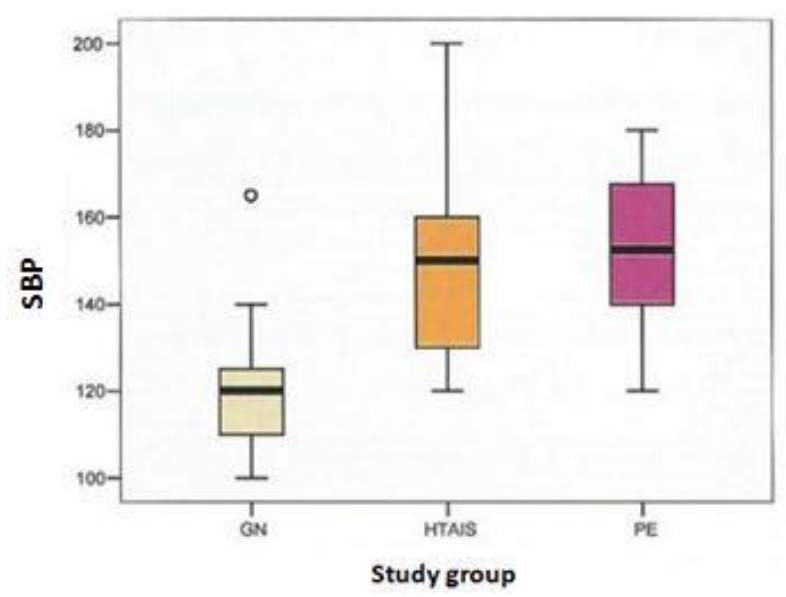

Fig. 3 Systolic blood pressure distribution within the study group

Diastolic blood pressure (DBP) was significantly higher in pregnant women in the preeclampsia group $(\mathrm{p}<0.001)$, with variations from 70 to $150 \mathrm{mmHg}$, the group average being $92.50 \pm 14.83 \mathrm{mmHg}$. Most pregnant women in the preeclampsia group had diastolic blood pressure values between $85-100 \mathrm{mmHg}(35 \%)$, but a weight of $26 \%$ of the preeclampsia pregnant women had values above $120 \mathrm{mmHg}$. Pregnant women with HTAIS recorded TAD values in the range $60-120 \mathrm{mmHg}$, with a group average of $88.80 \pm 14.17 \mathrm{mmHg}$. In normal pregnancies, diastolic blood pressure varied in the range $55-115 \mathrm{mmHg}$, the mean value of the group being $72.56 \pm 11.09 \mathrm{mmHg}$ (Figure 4).

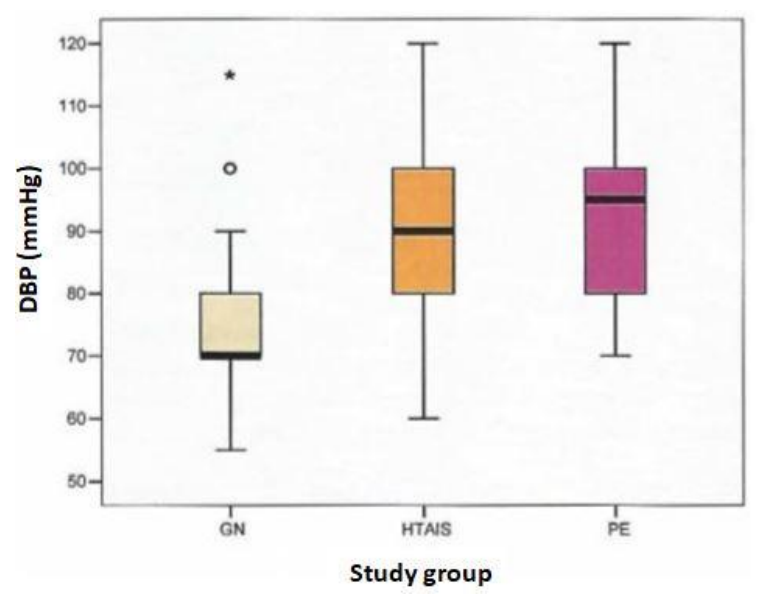

Fig. 4 Diastolic blood pressure distribution within the study group

Early detection of preeclampsia, not only on the basis of risk factor inventory but with the help of markers, could indicate more correctly when to start the treatment, its management or when to give birth. Motivated by the fact that these changes occur well before the onset of clinical signs of disease, the research in this field has intensified and recently has focused on endothelial dysfunction as a pathophysiological mechanism of preeclampsia.

In 2002, Chavarria states that the maternal plasma level of cellular fibronectin was evident several months before the onset of clinical signs. Its study in the case of preeclampsia has not been conclusive, or in other words additional studies or certain forms of fibronectin are required $(3,4)$.

Other researchers have studied the maternal inflammatory response in preeclampsia and especially in severe preeclampsia $(5,6)$, knowing that there is an exaggerated systemic maternal response. It is observed that a number of cytokines increase in preeclampsia such as: IL 6, 1NF alpha, IL IB, IL 8 as in SIRS (systemic inflammatory response to sepsis), but especially NO which, unlike systemic inflammatory response, in preeclampsia is low. So preeclampsia, 
at some point in evolution, borrows a link to the systemic inflammatory response, which is involved with endothelial dysfunction.

We note the following: IL 6 and $1 \mathrm{NF}$ alpha significantly increase in preeclampsia compared to normal pregnancies, IL 6 and IL IB significantly increase in severe preeclampsia compared to normal pregnancy, but for IL 6, IL 8, IL IB, $1 \mathrm{NF}$ alpha there are no differences significant between medium and severe preeclampsia. The conclusion of these studies is that increasing IL 6 and $1 \mathrm{NF}$ alpha may play a role in triggering from middle preeclampsia to severe preeclampsia, but further studies are needed to move these markers into clinical practice.

Closer to our practice and commonly used is a marker of C-reactive protein, that belongs to the acute phase protein group. It is synthesized by the liver and by RHS (the reticulo-histiocytic system) and does not cross the placental barrier. Increased CRP usually reflects the existence of an inflammatory, destructive, infectious or noninfectious, but non-specific process. Plasma normal concentration $<6 \mathrm{mg} \%$ increases with age and reaches a high level in pregnant women, middle inflammation, viral infections, bacterial and severe sepsis.

Depending on the increase in diastolic blood pressure, preeclampsia can be classified into 3 clinical forms: mild $(<100 \mathrm{mmHg})$; moderate $(100-110 \mathrm{mmHg})$; severe $(>110 \mathrm{mmHg})$.

The weight of $13 \%$ pregnant women with severe preeclampsia and $48.1 \%$ pregnant women with moderate preeclampsia are noted.

Severe forms of preeclampsia are found at older ages (25-43 years), on average around the age of 37, while moderate and mild forms are associated with mean ages of 28-29 years $(\mathrm{p}=0.020)$. If the average blood pressure exceeds $100 \mathrm{mmHg}$ there is an increased cardiovascular risk. In the case study, the severity of preeclampsia was observed at mean blood pressure values of approximately $155 \mathrm{mmHg}$; by comparison, mean TA values were 123 $\mathrm{mmHg}$ in the mean forms of preeclampsia and $109 \mathrm{mmHg}$ in the mild forms $(\mathrm{p}<0.001)$.

Nowadays, it is recognized that lowering salt, increased dietary intake of fruits and vegetables correlated with increased physical activity, weight loss, reduced alcohol consumption and quitting smoking can lower blood pressure in both genera. Most studies on high blood pressure excluded women who were breastfeeding or thinking about becoming pregnant. The current global trend in the management and prophylaxis of preeclampsia should take into account the benefits of lifestyle change as well as the prevention of chronic postpartum hypertension among women with preeclampsia (7).

Preeclampsia remains one of the most common diseases of pregnancy worldwide, with an incidence of about $5 \%$ of all pregnancies (8).

Although this disease is not yet fully known and curable, major advances have been made in identifying women at risk of triggering this disease and in preventing it $(9,10)$.

Early identification of patients at increased risk for developing preeclampsia is therefore one of the most important goals in obstetrics and can be achieved using several biochemical markers. They play the role of predictors or diagnostic tools and in the not too distant future even to track preeclampsia $(11,12)$.

A number of studies are providing recent data on the search for new biomarkers to diagnose preeclampsia. Proangiogenic factors such as VEGF, PIGF have been shown to deliver promising results. Also, retinol-binding protein444 and IL-1045 cytokine play an active and constant and quantifiable role in the pathogenesis of this disease. These biochemical markers have certain disadvantages such as the lack of test kits, inefficiency in early gestational stages, low specificity $(13,14)$.

\section{Conclusions}

Finding non-invasive biochemical markers in the blood or urine could predict the development or may help detect preeclampsia and thus be of particular importance. These biomarkers could have a decisive impact on the management of women and their pregnancies in order to prevent and even treat this disease. Early identification of women at risk of preeclampsia is a first step in this direction and has thus become a priority. Our study is associated with the current issues related to the screening of patients at risk and their approach through the necessity of changing their lifestyle during preconception, pregnancy and postpartum periods.

\section{References}

1.ROBERTS JM, TAYLOR RN, MUSCI TJ, RODGERS GM, HUBEL CA, McLAUGHLIN MK. Preeclampsia: an endothelial cell disorder. Am J Obstet Gynecol. 1989 Nov;161(5):1200-4.

2.GRILL S, RUSTERHOLZ C, ZANETTI-DÄLLENBACH R. et al. Potential markers of preeclampsia - a review. Reprod Biol Endocrinol. $2009 ; 7 ; 70$

3.SUD S, GUPTA I, DHALIWAL L, KAUR B, GANGULY N. Serial plasma fibronectin levels in pre-eclamptic and normotensive women. Int J Gynaecol Obstet 1999; 66: 123-128.

4.CHAVARRÍA ME, LARA-GONZÁLEZ L, GONZÁLEZ-GLEASON A, SOJO I, REYES A. Maternal plasma cellular fibronectin concentrations in normal and preeclamptic pregnancies: a longitudinal study for early prediction of preeclampsia. Am J Obstet Gynecol. 2002 Sep;187(3):595-601.

5.KANIKA MANDI CHOUDHURYA, MUNMUN DASB, SULEKHA GHOSH (SARKAR)C, DEBASIS BHATTACHARYAD, TAPAN KUMAR GHOSHE. Value of Serum $\beta$-hCG in Pathogenesis of Pre-Eclampsia. J Clin Gynecol Obstet. 2012;1(4-5):71-75. 
6.Cuciureanu DI, Statescu, C, Sascau RA, Cuciureanu T, Constantinescu VA, Hinganu D, Preda C, Hinganu MV, Turliuc MD. Particularities of Using Contrast Agents in Diagnosis of Stroke.Rev Chim (Bucharest), 70, no. 2, 2019, p. 685-688.

7.PARIKH NI, GONZALEZ J. Preeclampsia and Hypertension: Courting a Long While: Time to Make It Official. JAMA Intern Med. 2017 Jul $1 ; 177(7): 917-918$.

8.MONTE S. Biochemical markers for prediction of preclampsia: review of the literature. J Prenat Med. 2011;5(3):69-77.

9.TSATSARIS V, GOFFIN F, MUNAUT C, BRICHANT JF, PIGNON MR, NOEL A, SCHAAPS JP, CABROL D, FRANKENNE F, FOIDART JM. Overexpression of the soluble vascular endothelial growth factor receptor in preeclamptic patients: pathophysiological consequences. J Clin Endocrinol Metab. 2003;88:5555-5563.

10.TOMA AG, SALAHORU P, HINGANU MV, HINGANU D, DIMA-COZMA LL, PATRASCU A, GRIGORESCU C. Reducing the Duration and Improving Hospitalisation Time by Using New Surgical Tehniques and Psychotherapy. Rev Chim (Bucharest), 70, no. 1, 2019, p.143-146.

11.ROBINSON CJ, JOHNSON DD, CHANG EY, ARMSTRONG DM, WANG W. Evaluation of placenta growth factor and soluble Fms-like tyrosine kinase 1 receptor levels in mild and severe preeclampsia. Am J Obstet Gynecol. 2006;195:255-259.

12.HÎNGANU D, EVA I, STAN C, HÎNGANU MV. Morphological aspects of the rectal neovascularization in colorectal cancer - anatomicalsurgical and imaging implications.Rom J MorpholEmbryol2016; 57(1): 161-165.

13.SMADI S, POPOVICI I, COJOCARU I, BRAHA S, OCHIUZ L, DORNEANU O. Physico-chemical Characterization, Rheological Behaviour and Evaluation of Antifungal Activity of Propiconazole Nitrate Gels, Mat. Plast., 46, no. 1, 2009, p. 83-90.

14.PETLA LT, CHIKKALA R, RATNAKAR KS, KODATI V, SRITHARAN V. Biomarkers for the management of pre-eclampsia in pregnant women. Indian J Med Res. 2013;138(1):60-7.

$\overline{\text { Manuscript received: } 12.12 .2019}$ 